\title{
The Experience of Stigma in Nurses on the Early Spread of the COVID-19
}

\author{
Ice Yulia Wardani ${ }^{1 *} \mathbb{D}$, Nurlaila Fitriani ${ }^{2}$ D, Herni Susanti $^{1} \mathbb{D}$, Riska Amalya Nasution $^{3}$ D, M. Akbar Nugraha \\ ${ }^{1}$ Department of Mental Health Nursing, Faculty of Nursing, Universitas Indonesia, Depok, Indonesia; ${ }^{2}$ School of Nursing, \\ Faculty of Health Sciences, Universitas Muhammadiyah Surakarta, Surakarta, Indonesia; ${ }^{3}$ Department of Nursing, Faculty of \\ Medicine and Health Sciences, Universitas Jambi, Jambi, Indonesia
}

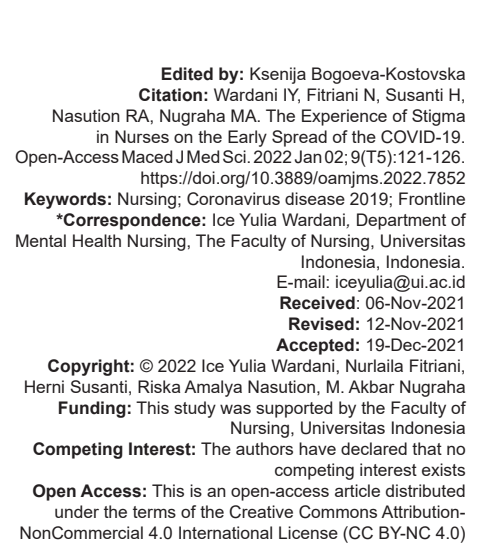

Abstract

BACKGROUND: Nurses are at the forefront of handling the coronavirus disease 2019 (COVID-19) and have a significant risk in handling the disease. The rapid transmission of the virus causes nurses to experience various mental health problems and stigma in performing their duties.

AIM: This study explored mental health conditions and the stigma of nurses at the forefront of handling the COVID- 19 .

METHODS: This research was a qualitative study with 17 nurses serving in hospitals and health centers in various provinces in Indonesia. The data analysis of this research employed a descriptive analysis technique.

RESULTS: The data analysis revealed four themes: Nurses carrying out their duties as a professional call, psychological and physical responses as a reaction to work stress, stigma due to running a profession, and social support as a reinforcement for carrying out their duties.

CONCLUSION: This study concludes that nurses require protection and guarantees for the work risk and the stigma consequences from the community.

\section{Introduction}

Mental health problems can occur due to various factors; one of them is an illness. At the end of 2019, China announced that the novel coronavirus disease 2019 (COVID-19) caused acute respiratory syndrome coronavirus. The COVID-19 is more contagious than SARS, and its case fatality rate $(2.3 \%)$ is much higher than that of seasonal influenza (the Novel Coronavirus Pneumonia Emergency) [1]. The COVID-2019 epidemic, especially in Wuhan China, attracted global attention. As of February 29, 2020, the National Health Commission of the People's Republic of China reported that 79,824 people from 31 provinces were diagnosed with the COVID-19, and 2870 died from this infectious disease [2].

Meanwhile, the Government of Indonesia reported that 2956 positive cases of COVID-19 were as of April 8, 2020 [3]. The rapidly increasing number of patients has forced health workers, especially nurses, to face a very large and high-risk workload that can cause mental health problems, such as anxiety, depression, and avoidance from the surrounding environment [4]. A survey on 4679 doctors and nurses in 348 hospitals in 31 provinces of China discovered the prevalence of psychological distress $(15.9 \%)$, anxiety symptoms (16\%), and depression (34.6\%) [5].

Nurses are health workers who are at the forefront of handling COVID-19. The COVID-19 pandemic is becoming a global health emergency that is causing stress to people and communities around the world. Stress about an illness can lead to social stigma against other people, places, or things. For example, stigma and discrimination can occur when people combine a disease, such as COVID-19, with a population in a region even though not everyone in that population or region is specifically at risk of developing the disease [6]. Stigma can also happen after someone leaves the COVID-19 quarantine period even though he is not considered a risk of transmitting the virus to others. Furthermore, communities or families of health workers may avoid them due to the stigma [7]. This situation becomes challenging and much more difficult [1]. Therefore, it is necessary to develop a definite step to help current psychosocial problems, including mental status and stigma experienced by health workers, especially nurses. 


\section{Methods}

\section{Research design}

This research was a qualitative study.

\section{Sample}

A qualitative study selected samples using a purposive sampling method; this method is conducted by selecting the desired place and participants and setting criteria of the research objectives [8].

\section{Data collection}

This research was a qualitative study and employed in-depth interviews for 30-60 min. This study involved 17 nurses from hospitals and health centers in various provinces in Indonesia (Table 1). The inclusion criteria for nurses were nurses on duty and caring for the COVID-19 patients. The data analysis employed the descriptive analysis technique.

\section{Data analysis}

The steps to analyze the research data were choosing an analysis method, analyzing interview data by selecting keywords, categories, tabulations, or combining them with sources to answer research questions, and perform an analytical framework, consisting of familiarizing, constructing a conceptual framework, indexing, charting, mapping, and interpreting data.

\section{Ethical considerations}

This research has been approved by the ethics committee of the University of Indonesia with the number: SK-190/UN2.F12.D1.2.1/ETIK2020.

\section{Results}

\section{profession \\ Theme 1: Stigma due to running a}

The findings showed that nurses were stigmatized when carrying out their profession. Their closest people, such as friends, the community, or the nurses themselves labeled them for being the COVID-19 carriers. During the COVID-19 pandemic, nurses have not had much time to interact in social spaces. They and their families are stigmatized as the COVID-19 carriers or infected people even though they show negative results. The research participants revealed the discrimination they received when carrying out their duties as frontline nurses. The statements of several participants are as follows.

"So, my friends accidentally did not respond to me, did not come near. You'll get infected even though she's acting. They did not want us to be close together. It seems that we're exiled because it's our own boarding house, right?" P15

"My friends kept me away because they said that I'm a nurse for a COVID-19 patient. They keep the distance and did not want to come closer." P2

"People are afraid of our family members even though the swab result was negative." P7

"I felt that I was not confident. I always question myself if my body was really healthy or if I was carrying the virus." $P 5$

\section{Theme 2: Psychological and physical} responses as a reaction to work stress

Several nurses expressed psychological and physical signs and symptoms emerging on their bodies when they worked as nurses at the forefront line of handling the COVID-19.

"It's scary if there are patients like this. And we frequently contact with them but there is no preparation for dealing with such patients." P15

"Besides that, we concern when we want to hold our face, we sometimes wash our hands three to four times before we dare to hold our face. Besides we don't dare to eat." P2

"Yes, because we know what the symptoms are, we frequently question ourselves "how am I like this, is my throat really like this?" though we do not suffer from the problems. It's just our feeling" P5

"Sometimes I feel cough, flu, and fever. Then, we associate it with the symptoms of the COVID-19." P9

\section{Theme 3: Nurses' dilemma as professional}

\section{duties}

Several participants mentioned their dilemmas while working at the forefront line of handling the COVID-19. This profession requires them to professionally provide nursing services.

"I didn't want to touch the patient because I was afraid of being transmitted or infected. But with the belief that in this case, we are helping, I ventured to serve patients and provide nursing actions for them." P1

"And in that field, as nurses, we do extraordinary work. We can say that nurses handling the COVID-19 work hard." P2 
Table 1: Characteristics of respondents

\begin{tabular}{llll}
\hline Initials & Gender & Work unit & Age (in years) \\
\hline P 01 & M & Hospital & 31 \\
P 02 & M & Hospital & 30 \\
P 03 & F & Hospital & 30 \\
P 04 & F & Health-care center & 41 \\
P 05 & F & ICU hospital & 27 \\
P 06 & M & Hospital & 37 \\
P 07 & F & Hospital & 27 \\
P 08 & M & Health-care center & 28 \\
P 09 & F & Hospital & 29 \\
P 10 & M & Hospital & 27 \\
P 11 & F & Hospital & 27 \\
P 12 & F & Health-care center & 27 \\
P 13 & F & Health-care center & 28 \\
P 14 & F & MPE & 31 \\
P 15 & F & Hospital & 29 \\
P 16 & M & Hospital & 29 \\
P 17 & M & Hospital & 28 \\
\hline
\end{tabular}

"Ah never mind if you want to get out of work. It's okay, but we think again that we are on duty." P7

\section{Theme 4: Social support as the reinforcement for carrying out nurses' duties}

Several participants explained that the surrounding people supported them in performing their duties as nurses at the forefront line of handling the COVID-19. "I got extraordinary support, especially from
my family." P15

"My close friends support me when I'm in the hospital. They still video call me." P4

"They encourage me through social media and also send me food." P10

\section{Discussion}

In the early days of the COVID-19 pandemic, the role of nurses was urgently needed and more highlighted than before. The COVID-19 pandemic has its own challenges for health-care professionals. For example, they have physical and psychological problems, such as stress, severe physical fatigue, and dilemmas between providing care and protecting themselves and their families while handling the COVID-19 patients. These conditions can decrease the quality of care for patients [9]. Nurses feel responsible for their duties because they uphold their profession. Their experiences require interventions to help them before, during, and after health-related crises. Therefore, they will be mentally and emotionally prepared to face challenges in their careers [10].

Nurses living with extended families feel that they are the virus carriers and limit their interaction with their close family. Moreover, some nurses prefer not to touch and hug their children and parents. Meanwhile, some others decide not to go home [11]. In addition to the dilemma in dealing with patients, nurses experience extraordinary stigma due to carrying out their duties as the frontline in handling the pandemic. Various forms of stigma are from outside and inside the nurses [7].

This study has proved that stress occurs in nurses with duties to treat the COVID-19 patients. This condition is similar to that in China, India, and Russia [12]. Various factors cause stress, such as insufficient knowledge, facilities, personal protective equipment, literature as the basic knowledge, and legal protection for nurses in carrying out their duties. Direct contact with infected patients is associated with a significantly increasing stress of medical personnel. The pandemic has compromised the psychological wellbeing of children and highly qualified specialists [12] The findings of this study indicate an alarming level of an insecure workplace of primary care nurses and serious problems of available personal protective equipment for nurses and other health workers. Perceptions related to the pandemic that decreases the quality of care are necessarily explored further to ascertain whether those with chronic conditions are supported to maintain and improve their health [13].

The study identified levels of psychological distress and associated factors, such as transmission from an infected person and psychological support. Nurses have received support from other nurses in social media or group chat to advise them and seek help from others. They also get support from friends and family on social media. When staff can access existing mental health services, it is common for staff with mental health problems to consider these services as an important resource for alleviating acute mental health disorders and improving their perceptions of physical health. This finding emphasizes the importance of being prepared to support frontline health workers through mental health interventions during times of widespread crisis.

Furthermore, the study was successful in identifying the level of psychological distress and factors, such as exposure to infected persons and psychological assistance. Social stigma in health negatively associates a person or group of people who have certain characteristics with illness. During a pandemic, social stigma means that people are branded, stereotyped, discriminated against, or treated differently from others, and even lose their status because they are thought to have a connection with the disease [14].

This study found that the COVID-19 pandemic has caused social stigma for nurses. This stigma ranges from family members to coworkers and community. Finally, there is an extra commitment beyond the nurses' current responsibilities. They serve under the most stressful conditions at the border between death and life [9]. Another qualitative research found that social stigma was an emerging theme for nurses caring for the COVID-19 patients; this condition shows that stigma and working under pressures directly affect nurses' mental health [15]. 
During the early spread of the COVID-19 pandemic, health workers experienced anxiety and stress from their work [16]. This study found that the difficulty of nurses is the number of shift work schedules that cause physical fatigue [9]. Other findings revealed that the number of patients increased during the COVID-19 pandemic, the working hours of nurses also increased 1.5-2 times from usual hours, and the workload also increased [17]. The protective clothing worn by nurses has contributed to this overwhelming fatigue. Wearing protective clothing for a long time makes them tired. They must wear heavy and warm clothing until the end of their shift [9]. Using personal protective equipment, such as coats, goggles, N95 masks, and gloves, makes it difficult for health workers on duty to drink water or to go to the toilet for 4-8 h. As a result, they easily feel uncomfortable (such as lack of oxygen), some use diapers, refrain from eating to avoid rest, shave their hair to reduce the spread of infection, and change personal protective equipment as quickly as possible. These activities create job stress for nurses who are in charge of caring for COVID-19 patients [18].

The findings of the psychological response of nurses caring for COVID-19 patients show that nurses experience fear of stigma from the community and people around them, anxiety about exposure, and the perceived burden of infection prevention and treatment efforts [13]. In general, they are stressed because of a heavy workload and are always exposed to risk factors due to various infectious diseases, biological hazards, carcinogens, increased work demands, and irregular work shifts [19]. Therefore, the emergence of infectious diseases inevitably adds to the stress for nurses [15].

Other findings show that many health-care providers experience mental-emotional disorders, such as depression, anxiety, insomnia, and stress. Moreover, more severe psychological problems occur in female nurses who are at the forefront [9]. Another finding shows a similar result that nurses have experienced many mental health problems because their work is quite stressful [20]. At the same time, they witness patients' deaths and are at risk from the rapid spread of the virus. Therefore, it can be concluded that their bodies and minds are under great stress [21]. This study also found that the negative psychological experiences of clinical nurses in the first line were caused by too much workload and heavy pressure, fear and anxiety, helplessness, and unfamiliarity with the environment and disease [22]. Another finding indicates a similar result that nurses experience multiple mental health problems because their work is quite stressful [23]. In addition, nurses at the forefront have symptoms of depression, anxiety, somatic symptoms, and suicidal ideation. This study discovered that the nurses at the forefront line of handling the COVID19 have suffered from mental health, and several factors of nurses' psychological health were identified [24].

Nurses show a very professional attitude in providing nursing services for patients. For nurses, this condition is related to their strong commitment to caring for others. They do not intend to leave the profession despite the stress, perceived risks, and inadequate support and protection in the workplace [25]. Therefore, early detection of psychological distress and supportive interventions to prevent more serious psychological impacts on frontline nurses handling the COVID-19 is crucial [26]. During the COVID-19 pandemic, nurses need more public awareness about complying with health protocols and social support to increase health workers' courage to deal with the COVID-19 pandemic.

Besides problems and challenges, nurses and professional nurses have opportunities during the COVID-19 outbreak. For example, they can improve their professional positions and understand the essence of nursing [9]. Other studies discovered that the COVID-19 has provided several opportunities for the development of professional nursing [17]: Love, compassion, honor, and respect for recognition, appreciation and gratitude to surrounding people, and active cooperation during patient care with COVID-19.

The above explanation confirms that the nurses need support from various parties, such as the government, related agencies, and the community to appreciate, maintain, and multiply the nurses' efforts while performing their duties during the COVID-19 pandemic.

The social support received during the COVID-19 pandemic helps nurses to reduce anxiety, reduce stress, and increase personal resilience in managing emotions which enable individuals to adapt positively in stressful situations and successfully bounce back during adverse circumstances. Another finding explains that social support from peers, friends, and family serves as an effective support system for nurses. This support system is especially important when some event triggers anxiety [27], [28]. The level of anxiety experienced is lower when social support is high. This shows that good social support can help nurses have a positive emotional state during the outbreak [28]. Another study that looked at the condition of doctors and nurses showed that anxiety, depression, and sleep disturbances were negative when they received high levels of social support. This shows that the psychological symptoms experienced by health workers can decrease by increasing social support during the COVID-19 pandemic. In addition, positive coping strategies and increased social support were associated with decreased nurses' psychological distress, increased self-efficacy, improved sleep quality, and decreasing levels of anxiety and stress [30], [31].

Physical problems, job stress, and psychological disorders can be overcome with social and psychological support; for example, psychological preparation to enhance their knowledge and skills [32]. Another study reveals the importance of strategy and interventions to reduce mental health impacts for nurses due to COVID 19 by providing protection, 
support, and improving the psychological well-being of the fron-tline health workers, including nurses, during a health crisis [32], [33].

Thus, to maintain the mental and physical health of nurses, managers should manage nurse schedules fairly, reduce workload and stress, provide necessary psychological interventions, train nurses to adapt to their respective psychological conditions, and provide psychological treatment during and after the pandemic COVID-19 [21].

The results of this study emphasize the importance of being prepared to provide full support for frontline nurses through nursing interventions, especially psychiatric nursing, during and after the crisis. National and international collaborations among the government, health systems, and health management are significant to ensure an optimal response and proper communication in future health emergencies. Moreover, they must always remember the importance of ensuring safety for professionals, patients, and communities.

\section{Conclusion}

This study has revealed that the nurses require protection and guarantees for the work risk and the consequences of the stigma in the community.

\section{Acknowledgments}

The researcher would like to thank the Faculty of Nursing, Universitas Indonesia, which has financially supported this research to complete this manuscript. Moreover, the authors appreciate all participants who volunteered for this study.

\section{References}

1. World Health Organization. WHO Coronavirus (COVID-19) Dashboard. Geneva: World Health Organization. Available from: https://covid19.who.int [Last accessed on 2020 Apr 08].

2. National Health Comission of China. Daily briefing on novel coronavirus cases in China. 2020 Available from: http://en.nhc. gov.cn/news.html [Last accessed on 2020 Apr 08].

3. Ministry of Health Republik Indonesia. Update COVID-19: Pasien Sembuh di Indonesia Kini 222, Bertambah 18. Direktorat Jendral Pencegahan dan Pengendalian Penyakit; 2020. Available from: http://www.p2p.kemkes.go.id/update-covid19-pasien-sembuh-di-indonesia-kini-222-bertambah-18 [Last accessed on $2020 \mathrm{Apr}$ 08].
4. Arnetz JE, Goetz CM, Arnetz BB, Arble E. Nurse reports of stressful situations during the COVID-19 pandemic: Qualitative analysis of survey responses. Int J Environ Res Public Health. 2020;17(21):1-12. https://doi.org/10.3390/ijerph17218126 PMid:33153198

5. Lai J, Ma S, Wang Y. Factors associated with mental health outcomes among health care workers exposed to coronavirus disease 2019. JAMA Netw Open. 2020;3(3):e203976-6. https:// doi.org/10.1001/jamanetworkopen.2020.3976

6. Salari N, Khazaie H, Hosseinian-Far A, Khaledi-Paveh B, Kazeminia M, Mohammadi M, et al. The prevalence of stress, anxiety and depression within front-line healthcare workers caring for COVID-19 patients: A systematic review and metaregression. Hum Resour Health. 2020;18(1):1-14. https://doi. org/10.1186/s12960-020-00544-1

7. Do Duy C, Nong VM, Ngo Van A, Doan Thu T, Do Thu N, Quang TN. COVID-19-related stigma and its association with mental health of health-care workers after quarantine in Vietnam. Psychiatry Clin Neurosci. 2020;74(10):566-8. https:// doi.org/10.1111/pcn.13120

PMid:32779787

8. Muller AE, Hafstad EV, Himmels J, Smedslund G, Flottorp S, Stensland S $\varnothing$, etal. The mental health impact of the covid-19 pandemic on healthcare workers, and interventions to help them: A rapid systematic review. Psychiatry Res, 2002: 293: 113441. https://doi.org/10.1016/j.psychres.2020.113441 PMid: 32898840

9. Creswell JW. A Concise Introduction to Mixed Methods Research. United Kingdom: SAGE Publications, 2014.

10. Galehdar N, Toulabi T, Kamran A, Heydari H. Exploring nurses' perception of taking care of patients with coronavirus disease (COVID-19): A qualitative study. Nurs Open. 2021;8(1):171-9. https://doi.org/10.1002/nop2.616 PMid:33318825

11. James SL. Global, regional, and national incidence, prevalence, and years lived with disability for 354 Diseases and Injuries for 195 countries and territories, 1990-2017: A systematic analysis for the Global Burden of Disease Study 2017. Lancet. 2018;392(10159):1789-858. https://doi.org/10.1016/ S0140-6736(18)32279-7

12. Alshammari FF, Ahamed ST, Abd S, Gawad E. On Patient Safety among Intern Nurses; 2020, https://doi.org/10.4103/ijhas.IJHAS

13. Sorokin AV, Karathanasis SK, Yang ZH, Freeman L, Kotani K, Remaley AT. COVID-19 associated dyslipidemia: Implications for mechanism of impaired resolution and novel therapeutic approaches. FASEB J. 2020;34(8):9843-53. https://doi. org/10.1096/fj.202001451

14. Ashley C, James S, Stephen C, Mursa R, Mclnnes S, Williams A, et al. Primary health care nurses' perceptions of risk during COVID-19: A qualitative study. J Nurs Scholarsh 2021;53(6):689-97. https://doi.org/10.1111/jnu.12698 PMid:34350686

15. World Health Organization. Stigma Sosial Terkait Dengan COVID-19. Geneva: World Health Organization; 2020.

16. Sadati AK, Zarei L, Shahabi S, Heydari ST, Taheri V, Jiriaei $R$, et al. Nursing experiences of COVID-19 outbreak in Iran: A qualitative study. Nurs Open. 2020;8(1):72-9. https://doi. org/10.1002/nop2.604 PMid:32904939

17. Cho KH, Kim B. Article the psychological responses of nurses caring for covid-19 patients: A methodological approach. Int J Environ Res Public Health. 2021;18(7):3605. https://doi. org/10.3390/ijerph18073605

PMid: 33807138

18. Sun N, Wei L, Shi S, Jiao D, Song R, Ma L, et al. A qualitative 
study on the psychological experience of caregivers of COVID-19 patients. Am J Infect Control. 2020;48(6):592-8. https://doi.org/10.1016/j.ajic.2020.03.018

PMid:32334904

19. Smith GD, Ng F, Li WH. COVID-19: Emerging compassion, courage and resilience in the face of misinformation and adversity. J Clin Nurs. 2020;29(9-10):1425-8. https://doi. org/10.1111/jocn.15231

PMid:32155302

20. Ratner PA, Sawatzky R. Health status, preventive behaviour and risk factors among female nurses. Health Rep. 2009;20:53. PMid:19813439

21. Gao X, Jiang L, Hu Y, Li L, Hou L. Nurses' experiences regarding shift patterns in isolation wards during the COVID-19 pandemic in China: A qualitative study. J Clin Nurs. 2020;29(21-22):4270-80. https://doi.org/10.1111/jocn.15464 PMid:32810919

22. Tan R, Yu T, Luo K, Teng F, Liu Y, Luo J, et al. Experiences of clinical first-line nurses treating patients with COVID-19: A qualitative study. J Nurs Manag. 2020;28(6):1381-90. https:// doi.org/10.1111/jonm.13095

PMid:32657465

23. Hong S, Ai M, Xu X, Wang W, Chen J, Zhang Q, et al. Immediate psychological impact on nurses working at 42 governmentdesignated hospitals during COVID-19 outbreak in China: A cross-sectional study. Nurs Outlook. 2020;69:6-12. https://doi. org/10.1016/j.outlook.2020.07.007

PMid:32919788

24. Sperling D. Ethical dilemmas, perceived risk, and motivation among nurses during the COVID-19 pandemic. Nurs Ethics. 2020;28(1):9-22. https://doi.org/10.1177/0969733020956376 PMid:33000673

25. Nie A, Su X, Zhang S, Guan W, Li J. Psychological impact of COVID-19 outbreak on frontline nurses: A cross-sectional survey study. J Clin Nurs. 2020;29(21-22):4217-26. https://doi. org/10.1111/jocn.15454 PMid:32786150

26. Foster K, Roche M, Giandinoto JA, Furness T. Workplace stressors, psychological well-being, resilience, and caring behaviours of mental health nurses: A descriptive correlational study. Int J Mental Health Nurs. 2020;29(1):56-68. https://doi. org/10.1111/inm.12610

PMid:31127973

27. Labrague LJ, De los Santos JA. COVID-19 anxiety among front-line nurses: Predictive role of organisational support, personal resilience and social support. J Nurs Manag. 2020;28(7):1653-61. https://doi.org/10.1111/jonm.13121 PMid:32770780

28. Jung $H$, Jung SY, Lee MH, Kim MS. Assessing the presence of post-traumatic stress and turnover intention among nurses postmiddle east respiratory syndrome outbreak: the importance of supervisor support. Workplace Health Saf, 2020;68(7):337-45. https://doi.org/10.1177/2165079919897693 PMid:32146875

29. Hou T, Zhang T, Cai W, Song X, Chen A, Deng G, et al Social support and mental health among health care workers during Coronavirus Disease 2019 outbreak: A moderated mediation model. PLoS One. 2020;15(5):e0233831. https://doi. org/10.1371/journal.pone.0233831

PMid:32470007

30. Yu H, Li M, Li Z, Xiang W, Yuan Y, Liu Y, et al. Coping style, social support and psychological distress in the general Chinese population in the early stages of the COVID-19 epidemic. BMC Psychiatry. 2020;20(1):1-11.

31. Xiao H, Zhang $\mathrm{Y}$, Kong D, Li S, Yang N. The effects of socia support on sleep quality of medical staff treating patients with coronavirus disease 2019 (COVID-19) in January and February 2020 in China. Med Sci Monit. 2020;26:e923549. https://doi. org/10.12659/msm.923549

PMid:32132521

32. Albott CS, Wozniak JR, McGlinch BP, Wall MH, Gold BS, VinogradovS.Battlebuddies:Rapiddeploymentofapsychological resilience intervention for health care workers during the COVID-19 pandemic. Anesth Analg. 2020;131(1):43-54. https:// doi.org/10.1213/ane.0000000000004912 PMid:32345861

33. Blake $H$, Bermingham $F$, Johnson $G$, Tabner A. Mitigating the psychological impact of COVID-19 on healthcare workers: A digital learning package. Int J Environ Res Public Health. 2020;17(9):2997. https://doi.org/10.3390/ijerph17092997

PMid:32357424 